Jurnal Media Agribisnis Vol. 2 No. 2 Tahun 2017 Hal 69 - 77

Media Komunikasi Hasil Penelitian Bidang Ilmu Agribisnis

ISSN print 2548-7027

ISSN online 2541-6898

\title{
PERBANDINGAN PENDAPATAN PETANI PADI \\ SISTEM SENAM DUPA (SEKALI TANAM DUA KALI PANEN) \\ DENGAN PETANI PADI SISTEM KONVENSIONAL DI KECAMATAN BERBAK KABUPATEN TANJUNG JABUNG TIMUR
}

\author{
Rizki Gemala Busyra ${ }^{1 *}$, dan Rogayah ${ }^{2 *}$ \\ ${ }^{1}$ Program Studi Agribisnis, Fakultas Pertanian Universitas Batanghari \\ ${ }^{2}$ Program Studi Agribisnis, Fakultas Pertanian Universitas Batanghari \\ Jl. Slamet Riyadi-Broni, Jambi. 36122. Telp. +6274160103 \\ *email korespondesi : qie_bs@yahoo.com
}

\begin{abstract}
One of the efforts to improve rice production and productivity In Provinsi Jambi is by using Senam Dua (Sekali Tanam Dua Kali Panen). Senam Dupa means one-time cultivation with two harvests, a rice-farming approach in tidal land that combines traditional rice cultivation systems (Crop Index 100 local rice varieties) with intensive farming (highyielding variety) in one overlay to achieve Crop Index 180. Kecamatan Berbak is one of the rice production centers in Tanjung Jabung Timur, Jambi. Senam Dupa has been introduced in order to increase rice production In Kecamatan Berbak. This is due to the tidal type of rice field in Kecamatan Berbak, and difficult water regulation, so it is not possible to plant two times. The increased rice production and productivity will be followed by increased farmers income. The purpose of this research are to know the income of rice farming that using Senam Dupa system and conventional system, and to see the difference of farmer income. This research uses primary data that obtained from farmer interviews with a questionnaire guide. Then the obtained data is tabulated and processed with SPSS software. The analysis methode used in this research is the difference of two means test methode. The results of this research indicate that Zhitung $(5,099) \geq Z$ tabel $(1,645)$, so that the hypothesis stating that the income of Senam Dupa is higher than the conventional rice farmers is acceptable. Senam Dupa rice farmers income Rp. 2,050,588,7/ha/month at 95\% degree of confidence significantly higher than the income of conventional rice farmers that is equal to Rp. 1.770.083.06 / Ha/month.
\end{abstract}

Keyword : Senam Dupa, Kecamatan Berbak, Farmer Income.

\begin{abstract}
Abstrak
Salah satu upaya peningkatan produksi dan produktivitas padi Di Provinsi Jambi adalah dengan cara Senam Dupa (Sekali Tanam Dua Kali Panen). Teknologi Senam Dupa diistilahkan dengan sekali menanam dua kali panen, yaitu sebuah pendekatan usaha tani padi di lahan pasang surut yang memadukan sistem budidaya padi tradisional (IP 100 varietas padi lokal) dengan pertanian intensif (varietas unggul) dalam satu hamparan sehingga mencapai IP 180. Kecamatan Berbak merupakan salah satu kecamatan sentra produksi padi yang terdapat pada Kabupaten Tanjung Jabung Timur, Jambi. Guna peningkatan produksi padi Di Kecamatan Berbak telah diperkenalkan sistem Senam Dupa. Hal ini dikarenakan jenis sawah pada Kecamatan Berbak adalah sawah pasang surut, dan
\end{abstract}


Jurnal Media Agribisnis Vol. 2 No. 2 Tahun 2017 Hal 69 - 77

Media Komunikasi Hasil Penelitian Bidang Ilmu Agribisnis

ISSN print 2548-7027

ISSN online 2541-6898

pengaturan tata air tidak mudah, sehingga tidak memungkinkan untuk melakukan penanaman dua kali. Peningkatan produksi dan produktivitas padi akan diikuti dengan peningkatan pendapatan petani. Tujuan penelitian adalah untuk mengetahui besarnya pendapatan usaha tani padi yang menerapkan sistem Senam Dupa dan sistem konvensional, serta melihat perbedaan pendapatan petani yang menerapkan sistem Senam Dupa dan petani yang menerapkan sistem konvensional. Penelitian ini menggunakan data primer yang didapatkan dari wawancara petani dengan panduan kuesioner, kemudian data yang diperoleh ditabulasi, dan diolah dengan software SPSS. Metode analisis yang digunakan adalah metode uji beda dua rata-rata. Hasil dari penelitian ini menunjukkan bahwa $\mathrm{Z}_{\text {hitung }}(5,099) \geq \mathrm{Z}_{\text {tabel }}(1,645)$ sehingga hipotesis yang menyatakan bahwa pendapatan petani padi sistem Senam Dupa yang lebih tinggi dari petani padi sistem Konvensional dapat diterima. Pendapatan petani padi sistem Senam Dupa Rp. 2.050.588,7 /Ha/bulan secara signifikan pada derajat kepercayaan $95 \%$ lebih tinggi dari pendapatan petani padi sistem Konvensional yaitu sebesar Rp. 1.770.083,06/Ha/bulan.

Kata Kunci : Senam Dupa, Kecamatan Berbak, Pendapatan Petani Padi.

\section{PENDAHULUAN}

Upaya peningkatan produksi pertanian utamanya padi masih dan akan tetap merupakan kebutuhan bagi bangsa ini, mengingat semakin meningkatnya kebutuhan pangan beras sejalan dengan meningkatnya penduduk dan kualitas hidup masyarakat. Agar tidak terjadi keadaan yang dapat mengganggu keberlanjutan sistem produksi padi, maka perlu ditempuh upaya-upaya peningkatan produksi dan produktivitas Padi guna terciptanya ketahanan pangan. Salah satu upaya peningkatan produksi dan produktivitas padi Di Provinsi Jambi adalah dengan cara Senam Dupa.

Provinsi Jambi merupakan salah satu provinsi penghasil padi di Indonesia. Pada Tabel 1 berikut dapat dilihat produksi dan produktivitas padi Di Provinsi Jambi. Pada Tabel 1 dapat dilihat bahwa Kabupaten Tanjung Jabung Timur (Tanjabtim) merupakan salah satu sentra produksi padi di Provinsi Jambi, yang memiliki luas panen sebesar $26.112 \mathrm{Ha}$, produksi 105.359 Ton dan produktivitas sebesar 4,03. Dilihat dari sisi produktivitas padi pada Kabupaten Tanjabtim masih berada dibawah rata-rata produktivitas Provinsi Jambi. Hal ini dikarenakan sebagian besar lahan di Kabupaten Tanjabtim adalah lahan rawa pasang surut yang mengakibatkan tingkat produksi padi belum optimal.

Kecamatan Berbak merupakan salah satu kecamatan sentra produksi padi yang terdapat pada Kabupaten Tanjabtim. Guna peningkatan produksi padi Di Kecamatan Berbak telah diperkenalkan sistem Senam Dupa. Hal ini dikarenakan jenis sawah pada Kecamatan Berbak adalah sawah pasang surut, dan pengaturan tata air tidak mudah, sehingga tidak memungkinkan untuk melakukan penanaman dua kali. 
Jurnal Media Agribisnis Vol. 2 No. 2 Tahun 2017 Hal 69 - 77

Media Komunikasi Hasil Penelitian Bidang Ilmu Agribisnis

ISSN print 2548-7027

ISSN online 2541-6898

\begin{tabular}{llccc}
\hline \hline \multicolumn{5}{l}{ Tabel 1. Luas Panen, Produksi dan Produktivitas Padi Provinsi Jambi 2015 } \\
\hline No & \multicolumn{1}{c}{ Kabupaten/Kota } & $\begin{array}{c}\text { Luas Panen } \\
(\mathrm{Ha})\end{array}$ & $\begin{array}{c}\text { Produksi } \\
\text { (Ton) }\end{array}$ & $\begin{array}{c}\text { Produktivitas } \\
\text { (Ton/Ha) }\end{array}$ \\
\cline { 2 - 5 } 1 & Kerinci & 28.727 & 160.222 & 5,58 \\
2 & Merangin & 16.484 & 71.573 & 4,34 \\
3 & Sarolangun & 14.693 & 58.050 & 3,95 \\
4 & Batanghari & 8.024 & 38.630 & 4,81 \\
5 & Muara Jambi & 10.579 & 48.880 & 4,62 \\
$\mathbf{6}$ & Tanjung Jabung Timur & $\mathbf{2 6 . 1 1 2}$ & $\mathbf{1 0 5 . 3 5 9}$ & $\mathbf{4 , 0 3}$ \\
7 & Tanjung Jabung Barat & 11.034 & 41.270 & 3,74 \\
8 & Tebo & 10.118 & 39.923 & 3,95 \\
9 & Bungo & 10.778 & 49.088 & 4,55 \\
10 & Kota Jambi & 1.361 & 6.252 & 4,59 \\
11 & Sungai Penuh & 8.080 & 45.473 & 5,63 \\
\hline & Jumlah & 145.990 & 664.720 & \\
\hline & Rata-Rata & $13.271,9$ & $60.429,1$ & 4,55 \\
\hline
\end{tabular}

Sumber: Jambi Dalam Angka, 2016

Lahan pasang surut mempunyai potensi yang besar untuk menghasilkan produksi pertanian dengan produktivitas tinggi, apabila dilakukan dengan menerapkan teknologi spesifik lokasi yang didukung oleh iklim agribisnis yang kondusif. Salah satu teknologi yang sudah diterapkan dan berkembang di lahan pasang surut Kecamatan Berbak adalah teknologi Senam Dupa. Teknologi Senam Dupa diistilahkan dengan sekali menanam dua kali panen, yaitu sebuah pendekatan usaha tani padi di lahan pasang surut yang memadukan sistem budidaya padi tradisional (IP 100 varietas padi lokal) dengan pertanian intensif (varietas unggul) dalam satu hamparan sehingga mencapai IP 180.

Peningkatan produksi dan produktivitas padi akan diikuti dengan peningkatan pendapatan petani. Akan tetapi, walaupun teknologi Senam Dupa telah diperkenalkan sejak tahun 2012, belum semua petani di Kecamatan Berbak mengaplikasikan teknologi tersebut. Berdasarkan uraian di atas maka perlu dilakukan penelitian untuk mengetahui Perbandingan Pendapatan Petani Padi Sistem Senam Dupa Dengan Petani Padi Sistem Konvensional Di Kecamatan Berbak Kabupaten Tanjung Jabung Timur.

\section{METODOLOGI PENELITIAN}

Penelitian ini dilaksanakan di Kecamatan Berbak Kabupaten Tanjung Jabung Timur. Objek dari Kajian ini adalah usahatani padi sawah yang telah mengikuti sistem Senam Dupa dan yang tidak mengikuti sistem Senam Dupa. Ruang lingkup Kajian ini dibatasi pada gambaran pendapatan usahatani padi sawah, dan perbandingan pendapatan usahatani.

Data yang dikumpulkan dalam penelitian ini terdiri dari data primer dan data sekunder. Data primer bersumber dari petani sampel yang diperoleh melalui wawancara langsung dengan menggunakan daftar pertanyaan (kuesioner) yang telah disiapkan secara 
Jurnal Media Agribisnis Vol. 2 No. 2 Tahun 2017 Hal 69 - 77

Media Komunikasi Hasil Penelitian Bidang Ilmu Agribisnis

ISSN print 2548-7027

ISSN online 2541-6898

terstruktur sesuai dengan tujuan dari penelitian. Sedangkan data sekunder bersumber dari instansi terkait yang berhubungan dengan penelitian ini dan laporan-laporan hasil kajian. Metode yang digunakan untuk mengumpulkan data dalam penelitian ini menggunakan metode survey. Pengolahan data dilakukan dengan program komputer yaitu SPSS.

Populasi dalam penelitian ini terdiri dari dua populasi yaitu populasi petani Senam Dupa dan petani konvensional. Jumlah populasi petani Senam Dupa adalah sebanyak 225 petani dan jumlah populasi petani konvensional adalah sebanyak 180 petani.

Menurut Singarimbun dan Effendi (1998), bahwa ada tiga hal yang harus diperhatikan dalam menentukan besar kecilnya sampel yaitu : 1). Derajat keseragaman, 2). Ketelitian yang dikehendaki, 3). Biaya, waktu dan tenaga kerja yang tersedia. Kemudian menurut Winarno (1994), bila populasi cukup homogen, terhadap populasi di bawah 100 dapat digunakan sampel sebesar 50\%, bila populasi di atas 100 dapat diambil sampel sebesar 15\%, dan juga sampel manusia hendaknya di atas 30 orang besarnya. Berdasarkan pertimbangan di atas, pengambilan sampel diambil secara acak sederhana (Simple Random Sampling) dengan jumlah sampel petani Senam Dupa sebanyak 34 petani, dan petani konvensional sebanyak 31 petani.

Alat analisis yang digunakan dalam penelitian ini adalah berupa alat analisis deskriptif baik kualitatif maupun kuantitatif. Analisis deskriptif merupakan analisis yang dilakukan secara deskriptif yaitu merumuskan dan mengumpulkan data dengan cara mengiterprestasikan, sehingga memberikan keterangan gambaran yang ada, dan analisis kuantitatif adalah analisis data yang berupa angka atau bilangan (Azwar,1998).

Dalam menghitung pendapatan petani Senam Dupa dan petani konvensional terlebih dahulu harus diketahui jumlah penerimaan dan seluruh biaya yang dikeluarkan dalam usahatani padi. Rumus biaya total menurut Sudarman dan Algifari (2001) adalah sebagai berikut :

Di mana :

$$
\mathrm{TC}=\mathrm{TFC}+\mathrm{TVC}
$$

$\mathrm{TC}=$ Total Cost atau Total Biaya $(\mathrm{Rp} / \mathrm{Ha} / \mathrm{bulan})$

$\mathrm{TFC}=$ Total Fixed Cost atau Total Biaya Tetap (Rp/ Ha/bulan)

$\mathrm{TVC}=$ Total Variabel Cost atau Total Biaya Variabel $(\mathrm{Rp} / \mathrm{Ha} / \mathrm{bulan})$

Untuk mengetahui besarnya biaya tetap, dihitung berdasarkan nilai penyusutan alat yang digunakan, menggunakan rumus sebagai berikut (Sudarman dan Algifari, 2001):

$$
B P A=\frac{H \arg \text { a Alat }}{\text { Umur Ekonomis }} x \text { Jumlah Alat }
$$

Dimana:

BPA = Biaya Penyusutan Alat $(\mathrm{Rp} / \mathrm{Ha} / \mathrm{bulan})$

Menurut Samuelson dan Nordhaus (2003), untuk menghitung besarnya penerimaan yang diperoleh dapat digunakan rumus sebagai berikut:

$\mathrm{TR}=\mathrm{Pq} \cdot \mathrm{Q}$

Dimana:

$\mathrm{TR}=$ Total Revenue atau Total Penerimaan $(\mathrm{Rp} / \mathrm{Ha} / \mathrm{bulan})$ 
Jurnal Media Agribisnis Vol. 2 No. 2 Tahun 2017 Hal 69 - 77

Media Komunikasi Hasil Penelitian Bidang Ilmu Agribisnis

ISSN print 2548-7027

ISSN online 2541-6898

$\mathrm{Pq}=$ Price atau Harga Produk $(\mathrm{Rp} / \mathrm{Kg})$

$\mathrm{Q}=$ Quantity atau Jumlah Produksi (Ton/Ha/bulan)

Menurut Sudarman dan Algifari (2001), untuk menghitung pendapatan dapat digunakan rumus sebagai berikut:

Dimana:

$\mathrm{I}=\mathrm{TR}-\mathrm{TC}$

$\mathrm{I} \quad=$ Income atau Pendapatan $(\mathrm{Rp} / \mathrm{Ha} /$ bulan $)$

$\mathrm{TR}=$ Total Revenue atau Total Penerimaan $(\mathrm{Rp} / \mathrm{Ha} / \mathrm{bulan})$

$\mathrm{TC}=$ Total Cost atau Total Biaya $(\mathrm{Rp} / \mathrm{Ha} /$ bulan $)$

Analisis yang digunakan untuk melihat perbandingan pendapatan petani Senam Dupa dan petani konvensional digunakan uji beda dua rata-rata (Uji Z) menurut Djarwanto dan Subagyo Pangestu (1993), formulasinya adalah sebagai berikut :

Dimana:

$$
z=\frac{\left(\overline{x_{1}}-\overline{x_{2}}\right)}{\sqrt{\frac{S_{1}^{2}}{n_{1}}+\frac{S_{2}^{2}}{n_{2}}}}
$$

$$
S_{x_{i}}^{2}=\frac{\sum x_{x_{1}}^{2}-\frac{\left(\sum x\right)^{2}}{n_{x}}}{n_{x}}
$$

$n_{1}=$ Jumlah sampel dari petani Senam Dupa

$n_{2}=$ Jumlah sampel dari petani Konvensional

$\overline{x_{1}}=$ Rata-rata pendapatan dari petani Senam Dupa

$\bar{x}_{2}=$ Rata-rata pendapatan dari petani Konvensional

$S_{1}^{2}=$ Varians sampel petani Senam Dupa

$S_{2}^{2}=$ Varians sampel petani Konvensional

Dengan hipotesis statistik adalah :

$$
\begin{aligned}
& H_{0}: \overline{x_{1}}=\bar{x}_{2} \\
& H_{a}: \bar{x}_{1} \neq \bar{x}_{2}
\end{aligned}
$$

Hipotesis Operasional :

$H_{0}$ : Tidak ada perbedaan pendapatan petani Senam Dupa dan petani konvensional

$H_{a}$ : Pendapatan petani Senam Dupa lebih tinggi dari petani konvensional 
Jurnal Media Agribisnis Vol. 2 No. 2 Tahun 2017 Hal 69 - 77

Media Komunikasi Hasil Penelitian Bidang Ilmu Agribisnis

ISSN print 2548-7027

ISSN online 2541-6898

Dengan kaidah keputusan secara statistik dimana :

1. Apabila $z_{\text {hitung }}<z_{\text {tabel }}$ dengan $\alpha=5 \%$ maka $H_{0}$ diterima, dan Ha yang ditolak, dengan kaidah keputusan tidak ada perbedaan pendapatan petani Senam Dupa dan petani konvensional.

2. Apabila $z_{\text {hitung }} \geq z_{\text {tabel }}$ dengan $\alpha=5 \%$ maka $H_{0}$ ditolak, dan Ha yang diterima, dengan kaidah keputusan bahwa pendapatan petani Senam Dupa lebih tinggi dari petani konvensional.

\section{Identitas Petani Sampel}

\section{HASIL DAN PEMBAHASAN}

Adapun identitas petani yang akan dibahas dalam penelitian ini meliputi umur, tingkat pendidikan, jumlah tanggungan keluarga, penggunaan lahan petani. Umur petani padi sistem Senam Dupa berkisar antara 24 - 60 tahun dan umur petani padi sistem Konvensional berkisar antara 28 - 51 tahun.. Umur petani padi sistem Senam Dupa terbanyak pada selang kelas umur 45 - 51 tahun yaitu sebanyak 11 petani atau 32,4\%, dan umur petani terendah yaitu pada selang kelas umur 59 - 65 tahun yaitu sebanyak 1 petani atau 2,9\%. Sedangkan rata-rata umur petani padi sistem Senam Dupa adalah 44 tahun. Umur petani padi sistem Konvensional terbanyak pada selang kelas umur 32- 35 tahun yaitu sebanyak 7 petani atau 22,6\%, dan umur petani terendah yaitu pada selang kelas umur 36 - 39 dan 44 - 47 tahun yaitu masing - masing sebanyak 3 petani atau 9,6\%. Sedangkan rata - rata umur petani padi sistem Konvensional adalah 39 tahun. Hal ini berarti bahwa kemampuan kerja petani berada pada kondisi yang produktif untuk mengolah usahataninya (Soekartawi,2006).

Tingkat pendidikan Petani padi sistem Senam Dupa mulai dari SD sampai dengan S1. Sebagian besar tingkat pendidikan petani hanya SD, yaitu sebanyak 25 petani atau sebesar 73,6\%. Tingkat pendidikan petani padi sistem Konvensional mulai dari SD sampai dengan SMA/SMK. Sebagian besar tingkat pendidikan petani adalah SMP/MTS, yaitu sebanyak 17 petani atau sebesar 54,8\%. Maka secara keseluruhan tingkat pendidikan petani di lokasi kajian dapat dikatakan tergolong rendah. Rendahnya tingkat pendidikan petani akan berpengaruh terhadap perencanaan dalam pengelolaan usahataninya, hal ini akan mempengaruhi tingkat produksi yang dihasilkan petani tersebut. Soeharjo dan Patong (1993), menyatakan bahwa semakin tinggi tingkat pendidikan petani maka kemampuan petani untuk meningkatkan pengelolaan usahataninya akan lebih baik terutama dari segi teknologi baru, pemahaman bercocok tanam dan pemasaran. Untuk mengatasi keadaan demikian, maka petani tersebut juga dapat memperoleh pendidikan melalui jalur non formal seperti kursus atau penyuluhan.

Sebagian besar petani padi sistem Senam Dupa memiliki tanggungan keluarga 4 orang yaitu sebanyak 16 petani atau sebesar 47,1\%. Petani sampel yang memiliki tanggungan keluarga paling sedikit adalah yang mempunyai tanggungan keluarga 6 orang yaitu sebanyak 1 petani atau sebesar 2,9\%. Sedangkan rata-rata jumlah tanggungan keluarga petani adalah sebanyak 4 orang. Petani padi sistem Konvensional memiliki tanggungan keluarga 4 orang yaitu sebanyak 16 petani atau sebesar 51,6\%. Petani yang memiliki 
Jurnal Media Agribisnis Vol. 2 No. 2 Tahun 2017 Hal 69 - 77

Media Komunikasi Hasil Penelitian Bidang Ilmu Agribisnis

ISSN print 2548-7027

ISSN online 2541-6898

tanggungan keluarga paling sedikit adalah 7 orang yaitu sebanyak 2 petani atau sebesar $6,5 \%$. Sedangkan rata-rata jumlah tanggungan keluarga petani adalah sebanyak 4 orang.

\section{Gambaran Usahatani Padi Sistem Senam Dupa dan Sistem Konvensional}

Senam Dupa merupakan kependekan dari Sekali Tanam Dua Kali Panen. Istilah semacam ini juga dikenal dengan Sawit Dupa atau Satu Kali Mewiwil Dua Kali Panen. Kedua Istilah ini merupakan generik dari padi ratoon. Ratoon adalah anakan padi yang muncul setelah indukannya dipotong. Padi ratoon sangat umum ditanam pada lahan rawa. Sesuai dengan agroekologi lahan yang tersedia, Senam Dupa sangat umum dilakukan di Kecamatan Berbak.

Usahatani padi sawah yang dilakukan petani satu kali dalam setahun menggunakan varietas lokal yang memiliki umur dan produktivitas yang rendah yaitu 1-2,5 ton/ha. Pertanaman padi petani di lapangan sering mengalami gangguan (OPT), terutama sundep, kepinding tanah dan burung, kualitas hasil masih kurang baik serta kelembagaan usahatani terlihat belum kondusif.

Kegiatan usahatani padi di Kecamatan Berbak, musim tanam dilaksanakan pada bulan September dan dipanen pada bulan Pebruari. Panen pada bulan Pebruari ini juga dikenal dengan istilah panen indukan. Panen ratoon dilaksanakan pada bulan April. Kegiatan panen padi ratoon ini menjadi perhatian Pemerintah Kabupaten Tanjung Jabung Timur. Guna mendukung peningkatan produktivitas, maka digulirkanlah bantuan berupa alat dan mesin pertanian (Alsintan), pupuk, obat-obatan dan lain-lain. Pada tahun 2016, tercatat 225 rumah tangga petani mengikuti program Senam Dupa. Kegiatan Senam Dupa ini juga tergolong intensifikasi, dimana input pemupukan dilakukan pada anakan padi agar dapat berproduksi optimal. Padi yang digunakan oleh masyarakat tergolong padi unggul lokal yang dikenal dengan nama Botol dan Sanapati. Produktivitas padi Senam Dupa panen indukan berkisar 1,5-3 ton/ha dan panen ratoon rata-rata 1,9 ton/ha.

\section{Gambaran Pendapatan Petani}

Pendapatan adalah penerimaan bersih petani padi yang merupakan selisih antara penerimaan hasil produksi dan biaya produksi total yang dikeluarkan untuk usahatani padi sawah. Aspek pendapatan ini merupakan sasaran akhir tujuan setiap program pemerintah karena berkaitan dengan kesejahteraan.

\subsection{Gambaran Pendapatan Petani Padi Sistem Senam Dupa}

Hasil produksi beras petani padi sitem Senam Dupa mencapai 1,9 Ton/Ha/MT, sehingga dengan rata-rata harga $\mathrm{Rp}$. 8.000,-/Kg maka penerimaan mencapai Rp. 18.611.029,4,-/MT. Berdasarkan rata-rata luas lahan di lokasi kajian yaitu 1,7 Ha maka penerimaan menjadi Rp. 15.142.034,3/Ha/MT. Dengan demikian penerimaan per hektar per bulan adalah Rp. 2.523.672,4.

Biaya produksi merupakan total dari biaya tetap dan biaya tidak tetap. Biaya produksi total rata-rata petani sitem Senam Dupa mencapai Rp. 7.286.415,97,-/MT atau setara dengan Rp. 5.598.745,02,-/Ha/MT. Dengan demikian pendapatan dapat diketahui dengan melihat selisih antara penerimaan dan biaya total produksi. Dalam hal ini pendapatan Rp. 
Jurnal Media Agribisnis Vol. 2 No. 2 Tahun 2017 Hal 69 - 77

Media Komunikasi Hasil Penelitian Bidang Ilmu Agribisnis

ISSN print 2548-7027

ISSN online 2541-6898

11.324.613,4,-/MT atau setara dengan Rp.9.543.289,3,-/Ha/MT. Maka pendapatan per hektar per bulannya adalah Rp. 2.050.588,7,-. Untuk lebih jelas dapat dilihat pada Tabel 2.

Tabel 2. Penerimaan, Total Biaya Produksi dan Pendapatan Petani Padi Sistem Senam Dupa

\begin{tabular}{lccc}
\hline Satuan & Penerimaan & $\begin{array}{c}\text { Total Biaya } \\
\text { Produksi }\end{array}$ & Pendapatan \\
\hline Per MT & $18.611 .029,4$ & $7.286 .415,97$ & $11.324 .613,4$ \\
Per Ha Per MT & $15.142 .034,3$ & $5.598 .745,02$ & $9.543 .289,3$ \\
Per Ha Per Bulan & $2.523 .672,4$ & $473.083,69$ & $2.050 .588,7$ \\
\hline
\end{tabular}

Ket: MT = 6 Bulan

Sumber : Data Olahan Primer, 2017

\subsection{Gambaran Pendapatan Petani Padi Sistem Konvensional}

Hasil produksi beras petani padi sistem Konvensional mencapai 3,79 ton/MT, sehingga dengan rata-rata harga Rp.7.158,06 /Kg maka penerimaan mencapai Rp. 27.057.258,06,- /MT. Berdasarkan rata-rata luas lahan di lokasi kajian yaitu seluas 1,9 Ha maka Penerimaan menjadi Rp. 16.487.231 /Ha/MT. Dengan demikian penerimaan per hektar per bulan adalah Rp. 2.060.903,9,-.

Total biaya produksi rata-rata petani padi sistem Konvensional mencapai Rp. 1.488.774,19 /MT atau setara dengan Rp. 916.930,11 /Ha/MT. Dengan demikian pendapatan yang merupakan selisih antara penerimaan dan biaya total produksi adalah Rp. 25.074.062,96/MT atau setara dengan Rp.15.550.629,63 /Ha/MT. Maka pendapatan per hektar per bulannya adalah Rp. 1.770.083,06. Untuk lebih jelas dapat dilihat pada Tabel 3.

Tabel 3. Penerimaan, Total Biaya Produksi dan Pendapatan Petani Padi Sistem Konvensional

\begin{tabular}{cccc}
\hline Satuan & Penerimaan & $\begin{array}{c}\text { Total Biaya } \\
\text { Produksi }\end{array}$ & Pendapatan \\
& & $1.488 .774,19$ & $25.074 .062,96$ \\
Per MT & $27.057 .258,06$ & $916.930,11$ & $15.550 .629,63$ \\
Per Ha Per MT & 16.487 .231 & $290.820,83$ & $1.770 .083,06$ \\
\hline
\end{tabular}

Ket: MT $=8$ Bulan

Sumber : Data Olahan Primer, 2017

\section{Perbandingan Pendapatan Petani Padi Sistem Senam Dupa Dengan Petani Padi Sistem Konvensional.}

Perbandingan sistem Senam Dupa dengan sistem Konvensional terhadap pendapatan petani dapat dilihat dari ada tidaknya perbedaan antara pendapatan petani padi sistem Senam Dupa dengan petani padi sistem Konvensional. Dalam hal ini diduga bahwa pendapatan petani padi sistem Senam Dupa lebih besar dari pendapatan petani padi sistem Konvensional.

Hasil analisa menunjukkan bahwa $Z_{\text {hitung }}(5,099) \geq Z_{\text {tabel }}(1,645)$ sehingga hipotesis yang menyatakan bahwa pendapatan petani padi sistem Senam Dupa yang lebih tinggi dari 
Jurnal Media Agribisnis Vol. 2 No. 2 Tahun 2017 Hal 69 - 77

Media Komunikasi Hasil Penelitian Bidang Ilmu Agribisnis

ISSN print 2548-7027

ISSN online 2541-6898

petani padi sistem Konvensional dapat diterima. Dalam hal ini pendapatan petani padi sistem Senam Dupa Rp. 2.050.588,7 / Ha/bulan secara signifikan pada derajat kepercayaan 95\% lebih tinggi dari pendapatan petani padi sistem Konvensional yaitu sebesar Rp. 1.770.083,06/Ha/bulan. Dengan demikian hasil analisa menunjukkan bahwa sistem tanam padi Senam Dupa memberikan dampak terhadap peningkatan pendapatan petani sebesar $15,85 \%$.

\section{KESIMPULAN}

Berdasarkan hasil dan pembahasan dapat ditarik kesimpulan sebagai berikut:

1. Pendapatan petani padi sistem Senam Dupa Rp. 2.050.588,7 /Ha/bulan lebih tinggi dari pendapatan pendapatan petani padi sistem Konvensional yaitu sebesar Rp. 1.770.083,06 /Ha/bulan. Dengan demikian hasil analisa menunjukkan bahwa sistem tanam padi Senam Dupa memberikan dampak terhadap peningkatan pendapatan petani sebesar $15,85 \%$.

2. Terdapat perbedaan pendapatan petani padi sistem Senam Dupa dengan petani padi sistem konvensional. Hasil kajian menerima hipotesis alternatif $\left(\mathrm{H}_{\mathrm{a}}\right)$ yaitu Pendapatan padi sistem Senam Dupa lebih tinggi dari pendapata petani padi sistem Konvensional.

\section{DAFTAR PUSTAKA}

Badan Pusat Statistik Provinsi Jambi. 2016. Jambi Dalam Angka. Badan Pusat Statistik Provinsi Jambi. Jambi.

Dinas Pertanian Kabupaten Tanjung Jabung Timur. 2016. Dinas Pertanian Tanaman Pangan Dalam Angka. Dinas Pertanian Kabupaten Tanjung Jabung Timur. Kabupaten Tanjung Jabung Timur.

Hernanto, F. 1996. Ilmu Usahatani. Penebar Swadaya. Jakarta.

Husein Umar. 2007. Metodelogi penelitian untuk Skripsi Dan Tesis Bisnis. PT. Raja Grafindo Persada. Jakarta.

Nazir, M. 1999. Metode Penelitian. Ghalia Indonesia jakarta.

Samuel, P.A, dan Nordhaus, W.,D. 2003. Ekonomi. Erlangga. Jakarta.

Singarimbun, M., dan Sofian E. 1998. Metode Penelitian Survai. LP3ES. Jakarta.

Soeharjo, A. dan Patong. 1993. Faktor - Faktor Produksi Padi. Penebar Swadaya. Jakarta.

Soekartawi. 2006. Analisis Usahatani. Jakarta.Universitas Indonesia. Jakarta.

Sudarman, Ari., dan Algifari. 2001. Ekonomi Mikro-Makro. BPFE. Yogyakarta.

Winarno, S. 1994. Pengantar Penelitian Ilmiah. Kanisius. Bandung. 